We do not have an information-prone society. When faced with a problem or interest, I suggest, we are more prone to ask, "What do I have to do?" rather than, "What do I have to know?" Part of this reaction is probably due to the fact that when we ask "What do I have to know?" we are faced with another problem in addition to the initial one; i.e., where to get the information. This added effort simply confirms in us our indifference to information, and we take our best shot at solving the problem through decision and action. I sometimes think we have made a virtue of the information incapacity by the way we laud decision making as an indicator of ability.

If the foregoing examples are reasonably accurate, we are then faced with a situation in which information is fundamentally important to societal and individual wellbeing, but is not perceived to be so by people in the conduct of their daily affairs.

Computer-supported telecommunications systems can be the instrument for accelerating information control by a few (this has been much of the trend, so far, as indicated by corporate, research, and technical use of these systems), or it can be used to build information confidence, use, and desire throughout society.

This option, I suggest, is central to the significance of telecommunications systems for a democratic society.

If the latter option is to be obtained, I suggest that information will have to be packaged and targeted so well on people's everyday problems and interests that it will be easier and more productive to say "What do I have to know?" before saying "What do I have to do?"

A basic approach to articulating an information service of this kind consists of the following steps:

1. Determine and prioritize the individual and societal problems and interests of a given community.

2. Ascertain the information parameters of those problems and interests.

3. Locate and obtain the information necessary to address those problems and interests.

4. Organize this information so as to optimally target the specified prob- lem or interest to be as easily retrievable as possible. This requires an understanding of the context in which the information is used so that it is optimally relevant, and an understanding of the language and problem articulation common to the individuals in the community in order to ensure rapid retrieval.

\section{A Lesson in Interactive Television Programming: The Home Book Club on QUBE}

W. Theodore BOLTON: OCLC, Inc., Columbus, Ohio.

On December 1, 1977, Warner Communications christened what has become the most publicized and talked about technological development in the field of cable television: QUBE, its two-way interactive cable system. Publicity posters claimed that this would be "a day you'll tell your grandchildren about," and broadcasters added the word "interactive" to their cocktail-party vocabulary. Academicians who ten years ago forecast a technological revolution initiated by the marriage of computer to cable television, smugly grinned and saw their dreams turn into reality.

Response to QUBE, however, has been mixed. Participatory television brings, to some, futuristic images of instant democracy; others warn of its potential demagogic power. ${ }^{1}$ Regardless of your critical persuasion, there now exists what former CBS executive turned Warner Amex ${ }^{2}$ consultant Mike Dann calls "a whole new utility." 3 This whole new utility, whether in the form of QUBE cable television, or some other combination of computer, cable television, telephone, and standard over-the-air broadcasting, will change the way we conduct our lives and interact with other people.

\section{THE HISTORY OF THE HOME BOOK CLUB}

Early in 1979, the OCLC, Inc., research staff appraised the nature and context of the QUBE facilities (located in Co- 
lumbus, Ohio, only five miles away). Discussions, which at times centered around far-fetched and lofty ideas, eventually led to realistic and inventive concepts that made use of QUBE's interactive technology. The most promising of these concepts was a book discussion program where the audience determined the content and direction of the discussion itself. Hoping to take advantage of this new technology, and at the same time expand library services available to the general public, OCLC proposed a book discussion program to QUBE.

In a previously released statement, QUBE Vice-President Harlan Kleiman had stated that the polling capabilities of the QUBE system should be treated like a "time bomb." 4 Yet OCLC's proposal indicated an interest in exploring these very same devices. This factor, coupled with QUBE's "closed door" policy toward outside researchers and scholars, seemed to indicated that the Home Book Club research proposal would be rejected. But QUBE executives did the unexpected: they agreed to air six Home Book Club programs, one each month. And so, on July 18, 1979, at 7 p.m., the Home Book Club premiered.

\section{AN INTERACTIVE BOOK DISCUSSION}

What makes QUBE unique is its twoway, or upstream, capability. The QUBE technology is made up of three complementary computers that are used for monitoring, tabulation, and billing purposes. Each QUBE console in a viewer's home has thirty channels to choose from and five response buttons to press when answering questions posed to home viewers on QUBE programs. By monitoring and tabulating data that show which TV sets are on, which programs viewers are watching, and which response buttons they last touched, QUBE therefore has a virtually error-free system of audience research. This allows for a staggering amount of audience data to be compiled theoretically every six seconds.

Apart from the thirty-channel capability of standard television, community programs, and pay-per-viewing feature films, the most intriguing aspect of QUBE is its five response buttons. OCLC felt that the use of these buttons should be emphasized and the concept of interaction should be fully incorporated into the Home Book Club. At the beginning of each Home Book Club program, home viewers were asked to select, from three alternatives, the opening topic of conversation about the book. After the home viewers had "touched in" their preference on one of the prespecified buttons, the QUBE polling computer tallied and displayed the results. Once the book discussion was under way, the home viewers were given additional opportunities to "democratically" determine whether the panelists should continue in a particular topic area, or move on to new topic areas.

If a controversial issue emerged within the course of a discussion, the Home Book Club panelists were encouraged to spontaneously pose interactive questions to home viewers. This form of instantaneous polling was extended to telephone participants who were also periodically incorporated into the book discussion. A sampling of these opinion-type questions included: from the Wifey program, "Should Sandy have left Norman?"; from the Metropolitan Life program, "Is this book too subjective for non-New Yorkers?"; from the Eye of the Needle program, "Was the violence portrayed a necessary part of this book?"; from the World According to Garp program, "Was this a feminist novel?"

Toward the end of each one-hour Home Book Club program the QUBE system broke new ground in interactive television history: home viewers selected, from five alternatives, the book to be discussed on next month's program. In addition, home viewers were able to request a copy of the book to be sent to their home at no charge from the Public Library of Columbus and Franklin County (PLCFC). These two transactions took place with a mere touch of the prespecified button on the QUBE console.

PLCFC provided a major contribution to the Home Book Club. Once the QUBE computers had compiled the names and addresses of those viewers who requested next month's book (earlier, all home view- 
ers had been told that their names would be entered in the QUBE computer if they responded to a book request), the QUBE computer printed the names on mailing labels. These labels were forwarded to the PLCFC Books-by-Mail Office, which then filled each request. The total time from "touch-in request" to "in-home mail delivery" was usually two to three days. Indeed, a form of electronic catalog ordering actually took place each time the Home Book Club program was cablecast in Columbus. It should be noted that Home Book Club viewers were also given the opportunity to order the alternative book choices.

\section{WHO WATCHED}

\section{THE HOME BOOK CLUB?}

An additional use of QUBE's two-way capability was also incorporated into the first six Home Book Club programs. Prior to selecting and ordering the next months' books, home viewers were asked to respond to a series of demographic-type questions. From these questions, a profile of the typical Home Book Club viewer was compiled to PLCFC and QUBE management. This portion of the program also provided the OCLC research department with data with which to explore the market-research potential of an interactive television system.

From the beginning of the Home Book Club research project, a few obvious limitations of interactive polling became apparent. First, not all home viewers made use of, or were willing to participate in, QUBE's interactive technology. Response rates ranged from 20 to 85 percent, with an approximate mean rate of 55 percent. Second, only one viewer in a multiple-person household could respond. Third, it can be logically assumed that certain kinds of people will and did interact more often than others.

Taking these limitations into consideration, a few generalizations were still able to be made regarding the Home Book Club audience. The demographic data traced over the first six programs showed the audience to be primarily composed of younger (below thirty-nine years of age), college-educated (65 percent had college or postgraduate degrees), middle to upper income (60 percent earning $\$ 25,000$ or more per year), females (approximately 70 percent of the interacting audience). These figures should not surprise anyone who is either familiar with previous profiles of the general library users or who may in passing conjure a guess as to what kind of person might be interested in viewing a televised interactive book discussion. A closer inspection of the instantaneous audience demographics, however, led to some disappointing implications.

\section{CAN A DEMOCRATIC TELEVISION PROGRAM SURVIVE?}

As was pointed out earlier, home viewers were permitted to select the next month's book at the conclusion of a program. This was strictly a democratic process where the majority ruled. The World According to Garp, the premier Home Book Club book, was followed by Eye of the Needle and Wifey for programs two and three respectively. The QUBE computer indicated that each of these programs were viewed by approximately 175 households, or almost 420 individuals. In a competitive structure where there are twenty-nine television program alternatives from which a viewer can choose, QUBE, OCLC, and the PLCFC felt that a successful programming concept had been born. QUBE management enthusiastically reported that the Home Book Club had achieved audience levels that at times rivaled their more extravagant and broadbased entertainment/interview program, "Columbus Alive."

This enthusiasm was short-lived as audience-level figures from program four came in. At the end of program three (Wifey), the audience selected James Michener's weighty novel Chesapeake for the next month's program. The respectable figure of approximately 375 viewers for Wifey dwindled to slightly less than 210 viewers for Chesapeake. And to make matters worse, the audience-level figures did not improve for programs five and six.

There are several alternative and sometimes complementary explanations for this substantial loss in audience. First, many viewers may not have been able to get 
through the some one thousand pages of "Maryland's Eastern Shore" history in Chesapeake, and thus chose not to participate in the Home Book Club. Second, the new fall syndicated programs offered at that time by local network affiliates may have led many viewers to choose alternative programming. Additional hypotheses can also be gleaned from the interactive demographic data: whereas in programs one through three approximately 40 percent of the audience indicated their educational level to be either some college or below, only 20 percent of the Chesapeake audience (program four) fell into this category. This statistic remained constant for programs five and six of the Home Book Club.

In the democratic television environment that the Home Book Club provides, what happens to the minority interest group? Could this democratic television system be systematically eliminating specific viewer types? It might be that the outvoted minority group book reader can withstand being overruled just so many times before ceasing to participate. What recourse does this minority interest group have other than to be dominated by higher-educated viewers who heavily stuff the electronic ballot box in favor of their own book preferences? Quite clearly the recourse for the minority interest group was to select a competing television program, as evidenced by the declining viewing audience-level figures. The loss of these viewers becomes especially disheartening because this particular audience segment may represent a group of individuals who never before participated in a book discussion.

\section{THE FUTURE OF THE HOME BOOK CLUB}

Given the somewhat disappointing results of the Home Book Club reported thus far, one would expect the program to be recorded in history as a noble, but unsuccessful, attempt at interactive television programming. The Books-by-Mail program did send out some 760 paperback books as a result of the Home Book Club (a 79 percent overall increase), and twenty-six new library cards (not a prerequisite) were issued to Home Book Club viewers. But the fact remains that a for-profit company such as Warner Amex most definitely cannot substantiate the continuation of a program that has the audience ratings as low as the Home Book Club. ... Or can it?

Not only has the Home Book Club been continued (it's now in its twentieth month), but a morning edition of the Home Book Club premiered in June 1980. What explanations can account for this somewhat bewildering corporate behavior? On a very idealistic level, Warner Amex could be fulfilling its obligation to serve all facets of the Columbus community. The Home Book Club certainly offers a viewing alternative to an often neglected segment of the viewing population. OCLC, Inc., and public libraries throughout the United States applaud this kind of responsible programming.

On a more practical level, there may be other strategies behind the renewal of the Home Book Club contract. A 1978 study completed by the Argus Research Corporation concluded that "no profits are expected from QUBE until the system is successfully replicated in cities other than Columbus, and at considerably lower costs."5 To replicate the QUBE system, Warner Amex must expand its cable territory into new communities throughout the United States. This can at times be a very difficult task.

The right for a company such as Warner Amex to wire a local municipality to its QUBE system is determined by local government. Normally, a city council reviews and contrasts alternative cable systems in terms of the services each system proposes in return for franchising rights. The final decision usually is based on costs, the programming made available, and, most importantly, the kind of community service the cable system proposes to extend to its viewers. One definition of extended community service might be a televised book discussion program that involves the local public libraries. The alluring notion of an interactive book discussion may even be more appealing to community-minded city council members. In fact, QUBE is currently using an edited composite tape of Home Book Club highlights in their franchising efforts. The success of such 
efforts remains to be seen. Whether Warner Amex's motives are community- or commercial-minded, the fact remains that other communities may have the opportunity to develop a program of this kind. Since local governments can legally specify what services the cable company must provide, the inclusion of a televised book discussion program could become part of a contract fulfillment. Advice for those interested in developing alternative television programs for special-interest groups: Don't be caught napping when your national cable representatives come knocking on your city council door.

As for the Home Book Club, QUBE and the Public Library of Columbus and Franklin County are working at reestablishing a solid baseline audience. As is the case for any television program, promotion is a key ingredient for success. When viewers were asked where they first found out about the Home Book Club, more than half indicated they obtained program information through the free Qube Program Guide. Approximately 15 percent heard from a friend and 12 percent found information at the public library. A coordinated promotional effort is highly recommended for a public-service program of this nature.

\section{THE FUTURE OF \\ INTERACTIVE TELEVISION}

QUBE must be thought of as more than just a two-way television system. In fact, it is more than interactive television. QUBE is actually a computer hooked to a cable communication system. That cable communication system is a network providing a pathway for a wide variety of services from central facility to home subscribers. In the future, not only will systems such as QUBE provide "local loop" communications for these services, but undoubtedly will be interconnected by a satellite with other similar systems throughout the country and indeed the world.

The five buttons on the existing QUBE consoles are just the first evidence of the future possibilities of interactive broadband communications systems currently delivering television. Because the early applications of cable were to provide entertainment television, and more often than not were provided by people in the television business, cable television is naturally oriented toward the entertainment business. But the future of these broadband communications systems is in interactive retrieval of information as much as it is in entertainment. This goes far beyond the simple polled system so frequently used in a two-way mechanism: the talk show host asks how many people have read a particular book, the audience responds, and the net result has no effect on the program itself. It is also a lot more than interactive television: the host asks what you want to discuss, the audience says the plot of the book, and the answer has an effect on the outcome of the show. In fact, these broadband communications systems have the potential for placing at the fingertips of Americans a vast storehouse of information services about, for example, the best auto routes to your favorite spots, baby care, banking, buying a house, dressmaking, good buys, hobbies, jobs, legal facts, properties for sale or rent, sports scores, technology, and wine.

As QUBE expands into its QUBE III system with more than a hundred channels of services, it will be technically positioned to support all aspects of this burgeoning information age ${ }^{6}$ Besides simple information retrieval, a QUBE subscriber will be able to conduct banking and shopping transactions, to provide information such as who is on what side of community issues, and also (incidentally) to watch television. If all of that does not seem like enough, remember that cable is really a very large pipe through which any variety of electronic information can be pushed. Passive home security, fire alarm, and energy management are also services either in existence or contemplated by a number of cable operators. For that matter there is no reason to believe the computer processing services can't be made available to individual subscribers. A subscriber could call up the program to balance his checkbook, to perform his smallbusiness payroll calculations, or to complete a statistical analysis of data for a school project.

Most people thought (as we initially did) that interactive cable (QUBE) means interactive television. But OCLC's research 
has shown that interactive television programs:

1. serve as an initial introduction to naive audiences of what a truly interactive system is all about;

2. are difficult to implement;

3. really aren't democratic;

4. are basically polling devices.

It has been said that the reason that railroads went out of business was because they insisted that they were in the railroad business and wouldn't admit that they were in the transportation business. If cable operators insist that they are in the television business, they may well miss the opportunities that are possible in the communications business or, in fact, in the information business.

By the same token, if libraries miss the significance of what cable television is bringing to their business, their role in the community will be diminished and libraries may go the way of railroads. Modern communications and computers offer an opportunity for libraries to become the information choice in their community. In the near future, applications such as the Home Book Club may well be a way to provide increased accessibility of library services to library patrons, and to "condition" those patrons to the coming electronic nature of libraries. Over the long term, libraries, if they have the courage and the foresight, can be the focus of the coming information and telecommunications revolution. The message is quite clear: opportunities abound.

\section{REFERENCES}

1. John Wicklein, "Wired City, U.S.A: The Charms and Dangers of Two-way TV," Atlantic Monthly 243:35-42 (Feb. 1979).

2. Warner Amex represents a newly formed corporation resulting from the merger of Warner Communications and American Express.

3. Jonathan Black, "Brave New World of Television," New Times 11:41 (24 July 1978).

4. Ibid., p.49.

5. "Warner Cable's QUBE: Exploring the Outer Reaches of Two-way TV," Broadcasting 95:28 (31 July 1978).

6. "Two-way Converters Hot Ticket at NCTA Exhibits," Broadcasting 97:72 (26 May 1980).

\section{An Informal Survey of the CTI Computer Backup System}

Joseph COVINO and Sheila INTNER: Great Neck Library, Great Neck, New York.

In order to help decide whether or not to purchase computer backup systems from Computer Translation, Inc. (CTI), * for use when the CLSI LIBS 100 automated circulation system is not operating, Great Neck Library conducted an informal survey of libraries using both systems. Eleven institutions, including both public and academic libraries, responded to a brief questionnaire. They were asked what size CTI system they had purchased and why, how easily it was installed, how well it performed, how it was maintained, and if CLSI acknowledged that the addition of the backup did not affect their LIBS 100 maintenance agreements.

Before summarizing the responses, the structure of the two systems and how they interact should be outlined.

\section{CLSI LIBS 100}

The CLSI automated circulation system consists of a stand-alone minicomputer console with local and/or remote terminals connected to it through individual ports by means of electrical and/or dedicated telephone line hookups. When it operates, the terminals are online and interactive with the database, which is stored on one or more multiplatter disc packs.

\section{CTI BACKUP}

The CTI backup system is based on an Apple II microcomputer with two minidisc

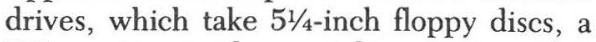
TV monitor, and a switching system that can be connected to the LIBS 100 console or its terminals. The CTI system can also be used alone. When the LIBS 100 is down (inoperative), the CTI system is connected to a terminal, and data is recorded on its discs for later dumping (data entry) into the database via a port connection. It

*CTI is a profit-making company wholly owned by Brigham Young University. The CTI backup system was originally developed to support the CLSI installation at BYU. 